\title{
INOVASI SISTEM ROBOTIKA PADA PERPUSTAKAAN
}

\author{
Kevin Prianka Ramadhani ${ }^{1}$, Yusuf Amrozi ${ }^{2}$, Irzaldi Adi ${ }^{3}$ \\ ${ }^{1,2,3}$ Program Studi Sistem Informasi, UIN Sunan Ampel Surabaya
}

Email: kevinprianka@gmail.com irzaldi804@gmail.com

\begin{abstract}
Abstrak - Tantangan perpustakaan pada era milenium saat ini adalah bagaimana perpustakaan tersebut dapat memudahkan pengunjungnya untuk mencari buku dengan waktu singkat. Pada saat ini perkembangan teknologi yang baru sangatlah dibutuhkan, apalagi pada abad 21 semua pekerjaan akan digantikan dengan adanya robot. teknologi robot inilah yang mulai saat ini dikembangkan oleh beberapa pihak untuk kemajuan peradaban manusia. Pada jurnal ini akan dibahas bagaimana teknologi robot bekerja pada lingkup perpustakaan dan bagaimana cara robot dapat bekerja sesuai yang diperintah. Hasil penelitian menunjukkan, terdapat beberapa perpustakaan dunia yang sudah menggunakan teknologi robot yang memudahkan pengunjung perpustakaan untuk mencari, mengambil dan mengembalikkan buku pada rak perpustakaan.

Kata kunci : robotika, perpustakaan
\end{abstract}

Abstract - The challenge of libraries in the current millennium is how the library can make it easier for visitors to find books in a short time. At this time the development of new technology is needed, especially in the 21st century all work will be replaced with a robot. this robot technology that began today was developed by several parties for the advancement of human civilization. In this journal, we will discuss how robot technology works in the scope of the library and how robots can work as instructed. The results showed, there are several world libraries that have used robotic technology that makes it easy for library visitors to find, retrieve and return books on the library shelves.

Keywords: robotics, library

\section{Pendahuluan}

Di masa depan akan muncul profesi-profesi baru dan tidak memungkinkan juga beberapa profesi akan menghilang. Profesi profesi itu menghilang bukan tanpa sebab, profesi itu menghilang dikarenakan kemajuan teknologi (disruptive technology) yang menggunakan mesin otomatisasi yang menggantikan pekerjaan manusia. Tetapi hal ini juga membawa hal positif bagi manusia karena dapat mempermudah segala hal yang berhubungan dengan produktivias. Perkembangan teknologi semakin pesat dikarenakan majunya pola pikir manusia yang semakin modern. Seiring berkembangnya teknologi, setiap perusahaan atau organisasi harus mengikuti perkembangan teknologi agar dapat bersaing di era globalisasi. Perkembangan teknologi ini juga mengantar kita ke era industri generasi keempat yang ditandai dengan munculnya komputasi awan, internet of things, artificial intelligence, mesin otomatisasi seperti, kendaraan tanpa pengemudi, khususnya robotika.

Perkembangan robot sejatinya sudah berjalan sangat cepat. Robot dibuat diharapkan memudahkan pekerjaan manusia yang selama ini memberatkan sebagian manusia. Beberapa robot yang telah dibuat bertujuan untuk menjalankan suatu pekerjaan dengan memiliki resiko yang sangat tinggi, yang dapat mengancam keselamatan manusia atau menyebabkan kematian. Robot juga didesain untuk mengerjakan pekerjaan kumuh atau kotor, pekerjaan dengan ketelitian dan kecepatan tinggi yang dilakukan secara berulang ulang.

Teknologi robotika sudah masuk dalam berbagai macam bidang seperti kedokteran, industri, Pendidikan. Contoh teknologi robotika di bidang kedokteran seperti robotic surgery. Lalu di bidang industri mereka menggunakan robotika atau mesin otomatisasi untuk memproduksi barang dalam jumah besar dengan cepat. Kemudian di bidang Pendidikan, mereka menggunakan teknologi robotika di berbagai bagian seperti sistem pembelajaran dan perpustakaan.

Dalam perkembangan robotik ini, banyak perusahaan maupun Universitas yang bersaing untuk mengembangkan dan memproduksi robot tetapi dengan biaya yang tidak murah dan membutuhkan waktu yang cukup lama. Oleh karena itu, salah satu tujuan penelitian ini adalah untuk mengetahui sejauh mana perkembangan teknologi robotika pada perpustakaan umum atau perpustakaan pada suatu Universitas terkenal di Dunia yang sudah menerapkan atau menggunakan teknologi robotika dalam mengatur perpustakaan umum atau perpustakaan Universitas.

Tercatat ada dua perpustakaan di Australia yang menggunakan robot untuk mengurus buku buku koleksi mereka, salah satunya adalah perpustakaan University of Technology Sydney (UTS), mereka menggunakan enam robot derek untuk mengatur ratusan ribu buku, membantu pengunjung dalam pengambilan buku di perpustakaan. Namun teknologi penyimpan yang dilakukan oleh University of Technology Sydney sepenuhnya 
menggunakan sistem penyimpanan dibawah tanah dengan menggunakan gelombang radio pada koleksinya. Sistem kerja ini mencontoh teknologi yang umum pada dipergunakan dalam transportasi dan logistik.

Sistem penyimpanan yang berada dibawah tanah selalu digunakan pada perpustakaan Eropa dimana ruangan sangat penting, namun mereka masih dioperasikan secara manual dan sangat lamban kerjanya. Teknologi seperti ini memungkinkan tersedianya ruang yang lebih banyak bagi buku populer yang sering kali dibaca atau dipinjam. Jikalau ada perpustakaan yang masih menggunakan rak rak buku yang tinggi, sistem robotika ini masih bisa berjalan dengan baik.

Sistem robotika ini menggunakan konsep seperti robot Humanoid, dimana pengunjung akan ditawari untuk mengambil buku atau dengan bantuan robot. Setelah pengunjung menginput permintaan buku yang diinginkan, robot tersebut akan berjalan dan mengambil buku pada rak rak perpustakaan dan mengantarkan buku yang diminta kepada pengunjung. Hal tersebut sangatlah memudahkan pengunjung, dimana pengunjung tidak perlu repot repot mengambil buku pada rak rak yang tinggi, walaupun perangkat komputer perpustakaan telah menampilkan hasil dimana buku tersebut diletakkan, hal tersebut masih memiliki kekurangan, yaitu pengunjung masih mencari secara manual buku yang dicari nya.

\section{Metode Penelitian}

Penelitian ini menggunakan metode deskriptif kualitatif, karena peneliti ingin menjelaskan tentang pemanfaatan invoasi robotika di perpustakaan untuk mempermudah berbagai pekerjaan yang ada di dalam perpustaakan tersebut.

Teknik pengumpulan data yang digunakan peneliti adalah studi literatur yaitu dengan cara mendapatkan informasi dan mempelajari teori yang berasal dari jurnal, skripsi, portal berita yang berhubungan dengan penelitian ini, sumber dari literatur ini tertera di daftar pustaka. Selain menggunakan metode studi pustaka, penelitian ini juga menggunakan bimbingan yang bertujuan untuk memberi tambahan atau koreksi dari dosen pembimbing untuk penelitian ini.

Teknik analisis data menggunakan analisi kualitatif yaitu pengumpulan data yang berupa kata-kata atau dokumen dan tidak menggunakan perhitungan untuk menganalisis data tersebut . Kemudian hasil dari analisi ini dapat ditarik menjadi informasi baru

\section{Pembahasan}

Robot adalah mesin yang dapat melakukan serangkaian Tindakan yang kompleks secara otomatis. Robotika sendiri sudah menyebar di berbagai aspek, mulai dari industri, pendidikan, kesehatan, dan kehidupan seharihari. Di pembahasan ini akan fokuskan pada robotika di perpustakaan khusunya perguruan tinggi. Perpustakaan merupakan tempat tersibuk di perguruan tinggi, oleh karena itu pelayanan yang ada juga harus memadai agar memuaskan para pengunjung. Robotika adalah solusi untuk meningkatkan pelayanan yang ada.

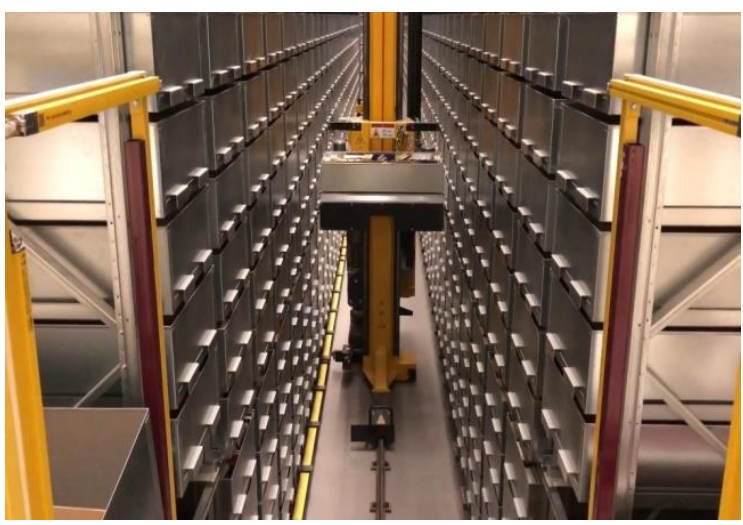

Gambar 1. Robot di Glucksman Library, University of Limerick.

Sumber : https://www.lib.ncsu.edu/huntlibrary/bookbot

Inovasi robotika sudah banyak diimplementasiakan di perpustakaan di seluruh dunia, seperti University of Limerick, perpustakaan yang bernama Glucksman Library mereka membuat ARC ( Automated Reserve Collection ), yaitu rak buku dan robot derek setinggi 10 meter yang bertujuan untuk penghematan ruang penyimpanan dan mempermudah pengunjung untuk pengambilan buku di perpustakaan tersebut.

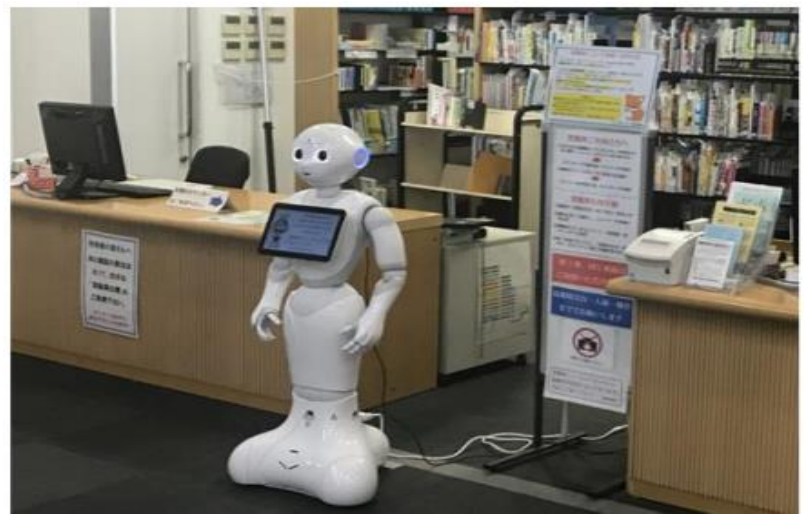

Gambar 2. Robot bernama paper yang berbentuk semi humanoid. Sumber : Raonoke.com

Jurnal yang berjudul Robotics and Artificial Intelligence Technology In Japanese Libraries, berisi pembahasan macam macam teknologi robotika yang ada di perpustakaan jepang. Robot bernama "Paper" adalah semi humanoid robot yaitu robot yang hampir seluruh penampilannya berbentuk manusia. Paper bekerja untuk mengarahkan dan memberi tahu informasi di tablet yang ada di dada paper kepada pengunjung. Paper juga dapat melakukan input buku di rak buku dan interaksi langsung dengan pengunjung karena paper dapat berbicara dan membuat Gerakan lucu. 


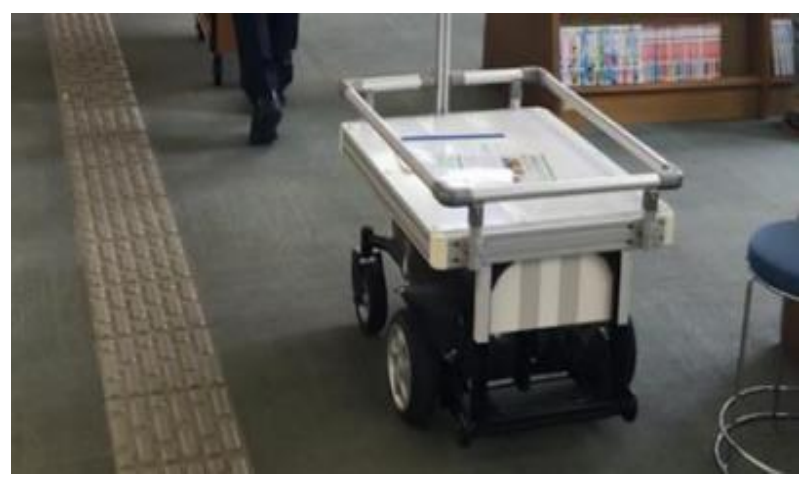

Gambar 3. Robot yang digunakan untuk mengembalikan buku. Sumber : google.com

Sebagai tambahan robot bernama Thouzer digunakan untuk mengumpulkan buku-buku dan ditempatkan di asalnya jika tidak ada pengunjung di perpustakaan tersebut.

Jurnal yang berjudul Robotic Grippers For Handling Books In Libraries, berisi pembahasan tentang perancangan robot untuk mengatur atau memanipulasi buku-buku yang ada di rak. Masalah manipulasi objek dipecahkan dengan menggunakan geometri yang standard dan terkenal dari lengan yang diartikulasikan yang dapat mengatur area dari suatu kondisi yang diinginkan. Dalam hal ini yang dimaksudkan adalah, suatu rancangan sistem robot dapat mengatur dan mengambil buku pada suatu area perpustakaan. Mengingat diatas, masalah manipulasi buku dapat diselesaikan seperti masalah manipulasi standar. Langkah dasar yang terkait dengan manipulasi atau mengatur buku dapat digambarkan sebagai berikut :

- Identifikasi buku (menurut judul, pengarang atau subjek) yang berhubungan dengan lokasi (dimana buku ditempatkan pada suatu rak)

- Memposisikan sistem robotik didepan buku untuk diambil dari rak

- Buku diambil dari rak

- Robot menuju unit transfer (lokasi rak ke lokasi pengguna)

- Pelepasan buku dan pengaturan kembali posisi buku

- Bagian dari buku yang dapat dilakukan pengambilan adalah bagian punggung buku

Pada perpustakaan Universitas Jaume-I Castellon, Spanyol, Suatu robot dibuat berbentuk seperti tangan yang terdiri dari 2 grip yang bisa bergerak kekiri dan kekanan. Jari jari ini bisa memegang buku dengan berat hingga 400g dengan ketebalan hingga 50mm. Robot pustakawan ini adalah robot layanan dengan ponsel prototipe manipulator yang dirancang untuk membantu tugas sehari hari. Sistem robot ini memiliki kamera dengan konfigurasi Megapixel Digital Stereo Head. Pada jari jari robot ini didesain seperti rahang dengan tatanan paralel. Robot ini dijalankan dengan cara robot berjalan menuju ke rak, lalu menggunakan kameranya untuk mengidentifikasi buku dengan waktu 5 s hingga 10 s per masing masing sentimeter buku untuk dipahami. Kemudian robot mengambil buku dengan jari jarinya untuk diantarkan kepada pengguna.

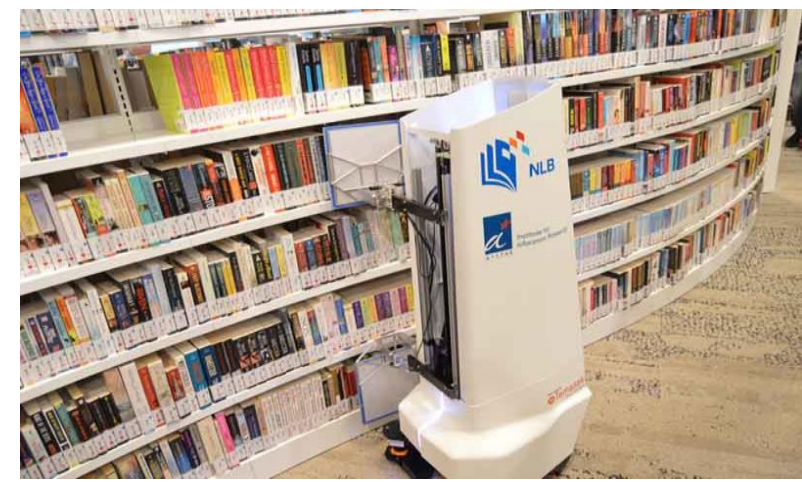

Gambar 4. Robot pada perpustakaan di Singapura.

Sumber : https://www.libraryjournal.com

Dalam hal mencari, mengidentifikasi dan mengekstrasi buku, robot ini juga dapat mengambil suara dari pengguna, jadi pengguna tidak perlu lagi mengetik pada suatu aplikasi, sistem robot ini akan otomatis mengenali suara yang diperintahkan. Hal ini juga berhubungan dengan sistem robot humanoid. Dalam percobaan lain, seorang manipulator menggunakan kekuatan/torsi dan sensor akselerasi yang dipasang dipergelangan tangan. Para peneliti melakukan pengujian kekuatan atau tekanan kontrol pada robot, dengan cara menempatkan sensor pada ujung jari robot lalu diuji dengan memperkirakan apakah kontak yang terjadi berjalan dengan baik ataukah berjalan dengan kasar (tidak ada respon). Dari pengujian tersebut, telah diimplementasikan sebagai berikut: 1.) Mengontrol kekuatan yang diterapkan menipulator pada buku melalui sensor pada ujung jari robot. 2.) Mencoba untuk memaksimalkan area kontak untuk memastikan bahwa kekuatan referensi dapat dibaca sensor. 3.) Mengekstrasi buku, dimana robot pada masa depan dapat melakukan tindakan baru untuk bisa menangani objek yang berbeda bentuk.

Robot pustakawan ini terdiri dari manipulator yang dapat mengenali dan memanipulasi buku dan platform seluler yang dapat menavigasi dirinya menggunakan tag yang tertanam pada lantai/permukaan. Hal ini menjelaskan bahwa permukaan/lantai pada perpustakaan harus memiliki tag jalur untuk robot tersebut. Hal ini dimaksudkan agar robot memiliki jalurnya sendiri untuk menuju rak buku. Oleh karena itu, dengan menggunakan penglihatan kamera pada grip atau jari jari, robot juga akan mengidentifikasi buku target melalui pengolahan gambar yang ditangkap oleh kamera dan sensor pada lengan robot.

\section{Kesimpulan}

Robot adalah mesin yang dapat melakukan serangkaian tindakan yang kompleks secara otomatis. Robotika sendiri sudah menyebar di berbagai aspek, salah satunya adalah perpustakaan. Implementasi teknologi robotika pada perpustaakan sangat penting karena membawa banyak manfaat yang diperoleh karena layanan-layanan yang diberikan. Seperti menghemat biaya operasional, kestabilan sistem, tidak terbatas oleh waktu. 
Penerapan teknologi robotika diperpustakaan sudah banyak dilakukan diberbagai negera seperti di Glucksman Library mereka menggunakan ARC ( Automated Reserve Collection ) yaitu rak dan robot derek untuk mengatur buku-buku secara otomatis. Diperpustaakan Jepang ada robot bernama Paper yaitu robot semi humanoid yang bertugas untuk menginput buku dan berinteraksi langsung dengan pengunjung perpustakaan, robot bernama Thouzer yang bertugas mengumpulkan buku-buku dan mengembalikan ketempat asal. Dan perancangan robot gripper, yaitu robot yang berbentuk seperti tangan yang bekerja untuk mengambil buku dan mengantarakan ke pengunjung perpustakkan.

\section{Daftar Pustaka}

[1] Aprilia Sari, Evi. (2019). Peran Pustakawan AI (Artifical Intellgent) Sebagai Strategi Promosi Perpustakaan Perguruan Tinggi Di Era Revolusi 4.0, Vol.3 No.1

[2] Beni A. 2011. Desain Pemodelan Kinematik dan Dinamik Humanoid Robot. Skripsi. Fakultas Teknik. Universitas Diponegoro: Semarang.

[3] Harada, Takashi. (2019). Robotics and Artificial Intelligence Technology In Japanese Libraries. Doshisha University, Kyoto, Japan.

[4] Monica, Corina., \& Gheorghe Leonte Mogan. (2015). Robotic Grippers For Handling Books In Libraries. Faculty of Mechanical Engineering. Transilvania University of Brasov, Romania.

[5] Tewkesbury, Giles \& David Sanders (1999). A new Simulation Based Robot Command Library Applied to Three Robots, Jurnal of Robotic System, Vol. 16, No. 8

[7] Kampus Ini Pakai Robot untuk Kelola Perpustakaan.

https://news.okezone.com/read/2015/11/10/65/ 1246634/kampus-ini-pakai-robot-untuk-kelolaperpustakaan diakses pada 16 April 2020.

[8] https://republika.co.id/berita/na2yv3/wowbukukoleksi-perpustakaan-universitas-teknologisydney-dikelola-enam-robot diakses pada 17 April 2020.

[9] https://www.wired.com/2011/05/robot-powered$\underline{\text { mansueto-library/ diakses pada } 25 \text { april } 2020 .}$ 